\title{
Analysis of the skeleton tension structure as the load-bearing structure of a one-nave hall
}

\author{
Przemysław Palacz*, Maciej Major \\ Czestochowa University of Technology, 42-200 Czestochowa, Poland
}

\begin{abstract}
In designing cubature buildings, an important stage is the selection of an appropriate construction solution, depending on the intended use and location of the designed building. When selecting the load-bearing structures, the designers strive to ensure that the structure weighs as little as possible, while meeting the strength conditions and ensuring the safe operation of the building. The article compares the loadbearing systems of the steel structure of a one-nave hall due to the economy of execution and meeting the ULS and SLS conditions. The analysis was carried out on four types of transverse system, including three frame systems with tendons and for a frame system with a lattice transom of the "N" type. Static calculations as well as dimensioning and optimization of the transverse load-bearing structures were performed in RFEM program, modelling the hall structure in 3D.
\end{abstract}

\section{Introduction}

When designing cubature building structures, the most important stage of works is the selection of an appropriate structural solution, depending on the purpose of the building and the conditions in which the designed building will be located. When choosing the right solution, the key factor is the cost of execution as well as economy and safety during operation. However, at the stage of selecting materials, designers choose such materials that the structure weighs as little as possible, while meeting all the load-bearing capacity conditions. Reinforced concrete structures in low-rise buildings are often selected types of structures due to the economy, however, in the case of high-rise buildings or halls with a large span, they show a significant own weight and there are difficulties in setting up the formwork, which is laborious and time-consuming, which results in the fact that it is no longer they are as economical as steel structures [1]. Steel structures are prefabricated structures, and the entire spatial structure is divided into shipping elements, which are made in manufacturing plants. The assembly connections between the shipping elements are realized as mechanical connectors, the so-called screws, which allows easy assembly on the construction site [2]. The use of steel structures is important for use in seismic zones where the forces transmitted to the structures are directly proportional to the weight of the structure. Steel structures are characterized by a high strength-to-weight ratio and can undergo significant plastic deformation before failure [1]. The own weight of steel structures is lower than that of reinforced concrete structures, which significantly reduces

\footnotetext{
${ }^{*}$ Corresponding author: przemyslaw.palacz@pcz.pl
} 
the cost of foundations, and the selection of an appropriate foundation is very important for the safe operation of the building and must be designed in such a way that the ground substrate does not show deformations under the influence of loads, and the lighter structures make it easier [3].

The development of civilization and the increasing requirements in terms of new technologies determine the search for new materials or new construction solutions, among others in civil engineering. By inventing new solutions, we strive for more and more effective use of materials and objects, so that the cost of construction and operation of buildings is as economical as possible, while meeting all the requirements in terms of cubic capacity and safe operation. In the article [4], the authors presented proprietary solutions with the use of 3D printing to increase the stiffness of thin-walled bars. As part of the research, it was shown that the self-locking insert, made in 3D printing technology, is an effective way to increase the stiffness of thin-walled C-profiles. Such solutions enable more effective use of smaller sections, which translates into a lighter and cheaper structure [4]. On the other hand, in articles [5-11], the authors presented the methods of connections in structures, comparing various solutions to demonstrate the most effective solutions ensuring adequate load-bearing capacity. Correctly designed assembly connections ensure adequate redistribution of forces to individual load-bearing elements, while maintaining optimal cross-sections ensuring sufficient load-bearing capacity, and this allows for effective use of the load-bearing capacity of all elements in the structure [5-11]. Steel is characterized by high tensile strength, so it is worth using these properties in tension structures where significant loads are transferred by tensioned tendons, most often made of round steel bars. Articles [12-14] present innovative solutions with the use of tensegrity structures. Tensegrity structures are spatial structures consisting of struts and ropes, and the integrity between them ensures a balance between the tensile forces in the ropes and the compressive forces in the struts [15]. Given that such systems have a relatively large amount of lightweight tension cables, such structures have a high strength-to-weight ratio, resulting in a strong and lightweight structure. In tension structures, the articulated systems consisting of cables transmit only axial forces, which significantly improves the stress distribution in individual bars. The use of tendons in the load-bearing frames significantly improves the redistribution of forces, which translates into more effective use of smaller cross-sections for individual load-bearing elements. The analysis carried out in the articles showed that tensegrity structures can have not only lower mass, but also lower stresses in individual bars than those in traditional structures, and the numerical examples show the effectiveness and legitimacy of using this solution in engineering structures [12-14].

The cost of construction, maintenance and operation of buildings is the basic factor in choosing the right construction solution. Customers always choose the most economical option, and the cost of steel structures is less than reinforced concrete structures. Steel structures do not require formwork, and the assembly of the hall from prefabricated elements is much faster. In steel structures, it is important to select the appropriate loadbearing structure depending on the requirements and conditions, so that the structure ensures safe and effective operation. The issue of effective use of internal cubature forces the use of new solutions and the use of external tendons in the hall construction scheme. The following part of the article presents an analysis of various construction schemes using tension structures, then assessed them in terms of their effective use and economy.

\section{Computational models of the analyzed load-bearing structures of the one-nave hall in a steel structure}

A one-nave hall with a gable roof with axial dimensions of $36.0 \times 48.0 \mathrm{~m}$, located in Poland, in Czestochowa, was adopted for the analysis. A structure was adopted consisting 
of 9 modular transverse systems with a span of $36.0 \mathrm{~m}$, spaced every $6 \mathrm{~m}$. The height of the extreme column in the axis was assumed to be $10 \mathrm{~m}$, and the roof slope was $10 \%$. The analysis was carried out on four types of transverse system, including three frame systems with tendons and one frame system with a lattice transom of the " $N$ " type. The spatial structures of the hall for each transverse system were modelled and calculated in RFEM 5 Dlubal Software, modelling the hall structure in 3D. An example calculation model is shown in Fig. 1.

In each model, the same external dimensions of the hall were assumed, steel grade S235 for all elements, roof and wall bracings were assumed in the extreme fields made of a bar with a diameter of $25 \mathrm{~mm}$. In the outermost walls, intermediate columns were additionally assumed, while the intermediate frame with the highest forces was analyzed. The roof purlins meeting the load-bearing capacity conditions were adopted from an IPE 200 Isection with a spacing of $3 \mathrm{~m}$, and for the roof and wall sheathing, a sandwich panel with a thickness of $160 \mathrm{~mm}$ and its own weight of $0.15 \mathrm{kN} / \mathrm{m}^{2}$ was used. The supports in the columns were assumed to be hinged, the tendons were modelled as tensile, and bar releases were applied in the nodes of the lattice rafter. Diagrams of each transverse system are shown in Fig. 2. The models were loaded in accordance with Eurocode 1 by own weight, live load, snow and wind. The atmospheric loads were assumed based on the location of the designed structure, which is located in the second snow load zone and in the first wind load zone according to Eurocode 1.

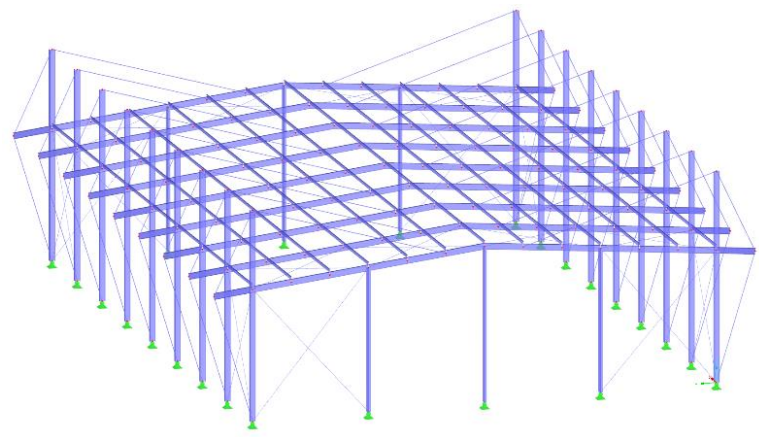

Fig. 1. Calculation model of the transverse system diagram with external tendons in RFEM 5 Dlubal Software.
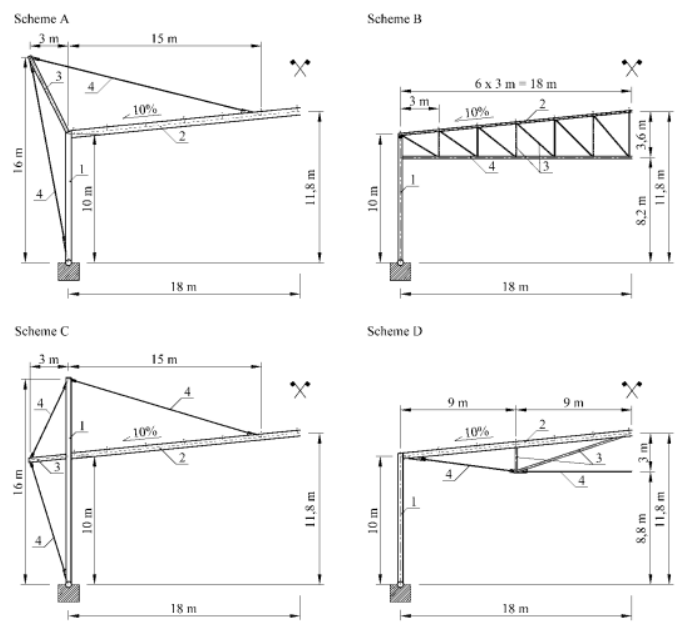

Fig. 2. Static diagrams of the analyzed load-bearing systems of the hall. The bar numbers refer to the information contained in tab. 1. 
In the next stage, FEM calculations were performed, and individual load-bearing sections were optimized on the basis of Eurocode 3 due to the ULS and SLS conditions for each design solution, while keeping the weight of the structure as low as possible. The weight of the structure translates directly into the costs of making the steel structure, but also reduces the costs of making foundation alloys, because with a lighter structure they transfer less loads to the ground. The analysis of the calculation results is presented in the further part of the article.

\section{Results and discussion}

As a result of the FEM analysis performed in the RFEM program, the design of steel members was performed according to Eurocode 3 by selecting the smallest possible crosssections meeting the ULS and SLS conditions. Table 1 shows the cross-sections for individual load-bearing elements of the transverse system along with the specified ULS and SLS conditions, mass and painting surface of one transverse system. Allowable deflections according to Eurocode 3 for columns are H/150 (where $H$ is the level of the considered rafter in relation to the top of the foundations), and for roof girders they are $\mathrm{L} / 250$ (where $\mathrm{L}$ is the span of the element). In roof girders, the SLS value is given for the entire girder. Deflection arrows were read in RFEM, then the deflection condition was converted to a percentage value.

Table 1. Results of ULS and SLS calculations, mass and painting area of one transverse system for each scheme. The bar numbering was adopted according to the diagrams in Fig. 2.

\begin{tabular}{|c|c|c|c|c|c|c|c|c|c|c|c|c|}
\hline \multirow[b]{2}{*}{ Bar No. } & \multicolumn{3}{|c|}{ Scheme A } & \multicolumn{3}{|c|}{ Scheme B } & \multicolumn{3}{|c|}{ Scheme C } & \multicolumn{3}{|c|}{ Scheme D } \\
\hline & $\begin{array}{l}\text { Cross- } \\
\text { section }\end{array}$ & $\begin{array}{l}\frac{2}{2} \\
\text { in } \\
5\end{array}$ & 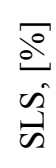 & $\begin{array}{l}\text { Cross- } \\
\text { section }\end{array}$ & $\begin{array}{l}\sqrt{0} \\
\hat{0} \\
\hat{0}\end{array}$ & 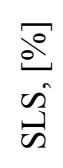 & $\begin{array}{l}\text { Cross- } \\
\text { section }\end{array}$ & $\begin{array}{l}\sqrt[0]{0} \\
\dot{0} \\
0\end{array}$ & $\begin{array}{l}\overrightarrow{0} \\
\dot{a} \\
\vec{n}\end{array}$ & $\begin{array}{l}\text { Cross- } \\
\text { section }\end{array}$ & $\begin{array}{l}00 \\
0 \\
0 \\
0 \\
0\end{array}$ & 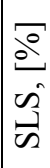 \\
\hline 1 & HEB 450 & 81 & 53 & HEB 280 & 63 & 87 & $\begin{array}{c}\text { HEB } \\
340 \\
\end{array}$ & 71 & 75 & HEB 340 & 53 & 99 \\
\hline 2 & IPE 550 & 82 & \multirow{3}{*}{72} & HEA 160 & 80 & \multirow{3}{*}{34} & IPE 450 & 89 & 53 & IPE 450 & 91 & \multirow{3}{*}{51} \\
\hline 3 & HEB 260 & 56 & & IPE 180 & 84 & & IPE 300 & 90 & & HEB 140 & 71 & \\
\hline 4 & $\square 60$ & 85 & & SP $70 \times 5$ & 91 & & $\square 60$ & 79 & & $\square 60$ & 84 & \\
\hline Mass & \multicolumn{3}{|c|}{$10023[\mathrm{~kg}]$} & \multicolumn{3}{|c|}{$4625[\mathrm{~kg}]$} & \multicolumn{3}{|c|}{$8810[\mathrm{~kg}]$} & \multicolumn{3}{|c|}{$7075[\mathrm{~kg}]$} \\
\hline $\begin{array}{l}\text { Painting } \\
\text { surface }\end{array}$ & \multicolumn{3}{|c|}{$142\left[\mathrm{~m}^{2}\right]$} & \multicolumn{3}{|c|}{$112\left[\mathrm{~m}^{2}\right]$} & \multicolumn{3}{|c|}{$136\left[\mathrm{~m}^{2}\right]$} & \multicolumn{3}{|c|}{$120\left[\mathrm{~m}^{2}\right]$} \\
\hline
\end{tabular}

Analyzing the results, it can be seen that the mass for the lattice transom scheme (scheme B) was the lowest among all the solutions. The deflection arrow of the lattice bolt also came out the smallest. However, attention should be paid to the laboriousness of execution, because the truss requires the most work due to the largest number of elements it consists of. In the case of full-walled roof girders, the work that needs to be devoted to the implementation of these elements is much less than when making a lattice transom. Comparing the schemes with full-walled transoms and tendons (schemes A, C and D), it can be noticed that in terms of weight and painting area, scheme $\mathrm{D}$ is the best solution, with 
internal tendons. It is also worth noting that the lattice transom (scheme B) with a height of $3.6 \mathrm{~m}$ and a full-wall girder with internal ties (scheme D) with a height of $3.0 \mathrm{~m}$, significantly reduce the usable space inside the hall, and in the case of solutions with external ties, this space is almost fully used, while maintaining the same external dimensions of the building. Effective use of cubature translates into operating costs, incl. for heating costs in winter and cooling in summer. Unused space devoted to the loadbearing girder in $\mathrm{B}$ and $\mathrm{D}$ frames requires additional energy for heating or cooling. In the perspective of long-term exploitation, this may translate into significant costs, and in the ecological aspect, higher energy consumption. The greater cost of making the transverse system with external tendons can compensate for the savings in heating / cooling the usable space, which will make this solution more effective and economical. Additionally, solutions with external tendons (schemes A and C) show greater transverse stiffness and significantly reduce the horizontal displacements of the hall compared to the load-bearing system with internal tendons (scheme D) and a lattice transom (scheme B). Comparing the diagrams with the external tendons (schemes A and C), a much better solution will be to use a tendon structure in which the tendons are mounted to the nodes on the extension of the column and transom (scheme C). This solution provides a much better distribution of forces, which results in a lower weight of the structure.

Analyzing the load-bearing systems in terms of the surface to be painted, the system with the lattice transom is also the best among all solutions, because it is characterized by the smallest surface to be painted. However, comparing the structures with the external tendons, scheme $\mathrm{C}$ is characterized by a smaller painting area. However, the difference between the values is insignificant.

\section{Conclusion}

The article presents a comparative analysis of four different design solutions for a steel onenave hall design. When choosing a material and construction solution, the key factors influencing the choice are economy of execution, ecology and operating costs. Investors always choose the most economical solutions, rejecting expensive and time-consuming structures. When choosing a structural solution for steel structures, the most important factor influencing the cost of its implementation is weight and labor consumption. With a low weight of the structure, the cost of the foundations will also be lower, as they will have to transfer less forces to the ground. By analyzing various schemes of design solutions, you can see how important a design stage is to choose the optimal load-bearing system, adapted to the requirements of the designed facility and the conditions in which the facility will be operated. However, bearing in mind the issues related to the effective use of the building's cubature, structures with external tendons allow the use of cubature to a much greater extent. With the same hall geometry, the lattice transom disqualifies the cost of the complexity of execution and is characterized by ineffective cubature, which translates into higher costs during the operation of the facility. The solution with the use of external tendons in the structural scheme is heavier, but simple to implement and is characterized by high efficiency of using the cubature, therefore in relation to the appropriate group of design solutions for a specific area and volume, such a tendon structure is a solution that should be taken into account during design.

\section{References}

1. Gagandeep, Chandigarh University, Mohali, Punjab 37, 2917-2920, 2214-7853 (2021).

Information on http://dx.doi.org/10.1016/j.matpr.2020.08.672 
2. A. Kozłowski, Konstrukcje stalowe, Przykłady obliczeń według PN-EN 1993-1 (Oficyna Wydawnicza Politechniki Rzeszowskiej, Rzeszów, 2010) (in polish)

3. P. Palacz, M. Major, Zeszyty Naukowe Politechniki Częstochowskiej, Budownictwo. 26, 120-125, 0526-5916 (2020). Information on http://dx.doi.org/10.17512/znb.2020.1.18

4. M. Kosiń, I. Major, M. Major, J. Kalinowski, Case Studies in Construction Materials. 13 (2020). Information on https://doi.org/10.1016/j.cscm.2020.e00401

5. P. Palacz, I. Major, MATEC Web Conf., Dynamics of Civil Engineering and Transport Structures and Wind Engineering (2020). Information on https://doi.org/10.1051/matecconf/202031300032

6. M. Major, J. Nawrot, I. Major, IOP Conference Series: Materials Science and Engineering $\mathbf{5 8 5}$ (2019). Information on https://doi.org/10.1088/1757899X/585/1/012007

7. I. Major, M. Major, K. Kuliński, Engineering Transactions 67(2), 199-211 (2019). doi:10.24423/EngTrans.1006.20190405

8. I. Major, M. Major, Z. Respondek, Archives of Metallurgy and Materials 63, 1, 491496 (2018). https://doi.org/10.24425/118966

9. I. Major, M. Major, Z. Respondek, Double-arm steel connector of glass façades, XXII International Scientific Conference "Construction the Formation of Living Environment" (FORM-2019), E3S Web of Conferences 97, 06012 (2019). doi.org/10.1051/e3sconf/20199706012

10. S.M.I.S. Zainal, F. Hejazi, R.S.M. Rashid, International Journal of Concrete Structures and Materials 15, 20 (2021). doi.org/10.1186/s40069-021-00457-w

11. Haibo Yang, Structures 28, 837-846 (2020). 2352-0142. doi.org/10.1016/j.istruc.2020.09.036

12. Ziyun Kan, Ningning Song, Haijun Peng, Biaosong Chen, Xueguan Song, International Journal of Solids and Structures 210-211, 289-309 (2011). doi.org/10.1016/j.ijsolstr.2020.11.015

13. Yan Su, Jingyao Zhang, Makoto Ohsaki, Yue Wu, International Journal of Solids and Structures 206, 9-22, 0020-7683 (2020). doi.org/10.1016/j.ijsolstr.2020.09.002

14. Yafeng Wang, Xian Xu, Yaozhi Luo, Engineering Structures 234, 0141-0296 (2021). doi.org/10.1016/j.engstruct.2021.111965

15. R.E. Skeleton, M.C. de Oliviera, Tensegrity Sysetems, Springer Dordrecht Heidelberg London New York, Springer, Boston, MA, 2009. doi.org/10.1007/978-0-387-74242-7 